\title{
RANCANG BANGUN TRAINER VARIABLE SPEED DRIVE (VSD) ANALOG DAN DIGITAL DENGAN SISTEM PENCACAH TEGANGAN PADA LABORATORIUM LISTRIK POLITEKNIK PENERBANGAN SURABAYA
}

\author{
Prasetyo Iswahyudi \\ Program Studi Diploma III Teknik Listrik Bandar Udara \\ Politeknik Penerbangan Surabaya \\ Jl.Jemur Andayani 1/73 Wonocolo Surabaya 60236 \\ Telp. (031)841087, Fax.(031)8490005
}

\begin{abstract}
ABSTRAK
Salah satu mata kuliah Program Studi Teknik Listrik Bandar Udara yaitu mesin listrik. Dalam mata kuliah tersebut terdapat materi tentang motor listrik, motor listrik adalah suatu alat yang berfungsi sebagai mesin penggerak dari berbagai peralatan listrik. Pada motor listrik ini terdapat suatu alat yang menjadi kontrol kecepatan putaran yaitu Variable Speed Drive (VSD). Variable Speed Drive memang difungsikan untuk mengatur putaran motor, sehingga motor tersebut dapat berputar sesuai dengan kebutuhan dari alat. Ada dua jenis VSD yaitu VSD dengan sistem pencacah tegangan dan VSD dengan sisem perubahan frekuensi. Pada VSD dengan sistem pencacah tegangan, putaran motor diatur dengan cara merubah input tegangan dari motor, perubahan tegangan ini diatur pada suatu rangkaian yang disebut rangkaian pembagi tegangan. Rangkaian pembagi tegangan terdiri dari beberapa komponen elektronik yaitu triac, diac, rangakaian timer dari resistor dan kapasitor. Triac berfungsi untuk mengatur besar tegangan dan kerja triac juga diatur oleh rangkaian time $R$ - $C$ atau rangakaian resistor kapasitor. Dengan mengatur time, output tegangan dari triac juga dapat berubah sehingga putarn motor juga dapat berubah.
\end{abstract}

Kata kunci: Variable Speed drive, rangkaian pembagi tegangan,rangkaian $R-C$, Triac.

\section{LATAR BELAKANG}

Perkembangan peralatan listrik telah mengalami pertumbuhan yang pesat, peralatan-peralatan baru mulai dari peralatan rumah tangga sampai peralatan pabrik hampir semua menggunakan peralatan listrik, sampai pada peralatan transportasi juga telah menggunakan sebagai tenaga listrik.

Sebagian besar peralatan rumah tangga ataupun pabrik yang menggunakan tenaga listrik seperti mesin cuci, mesin pengaduk, maupun sepeda listrik menggunakan motor listrik sebagai penggerak utama pada peralatan tersebut, mulai menggunakan motor DC sampai motor AC yang digunakan pada alat tersebut.

Seperti yang kita tahu penggerak agar dapat berfungsi haruslah dapat diatur mulai dari kecepatan maupun kekuatan dari penggerak, seperti kipas angin yang harus dapat berputar pelan sampai dengan putaran keras tergantung dari keinginan pengguna peralatan tersebut. 
Pada sebagian besar peralatan yang digunakan sebagai penggerak yaitu motor AC atau motor dengan sumber listrik arus bolak-balik. Sehingga perlu suatu alat yang dapat digunakan untuk mengatur kecepatan atau kekuatan supaya tenaga putaran motor dapat dioperasikan sesuai dengan keinginan pengguna peralatan listrik.

Peralatan untuk pengatur kecepatan motor listrik biasa disebut dengan Variable Speed Drive (VSD) atau inverter, peralatan ini berfungsi mengatur putaran motor dengan perubahan frekuensi dan jalan lain untuk mengatur putaran dapat pula dengan merubah tegangan sehingga penulis dapat membuat suatu alat sebagai pembelajaran di tempat studinya dengan konsep pengatur motor dengan sistem baru maka penulis mengambil judul tugas akhir "RANCANG BANGUN TRAINER VARIABLE SPEED DRIVE (VSD) ANALOG DAN DIGITAL DENGAN SISTEM PENCACAH TEGANGAN PADA LABORATORIUM LISTRIK POLITEKNIK PENERBANGAN SURABAYA".

\section{KONSEP DASAR RANCANGAN}

Konsep dasar rancangan Variable Speed Drive ini yaitu gelombang tegangan tiga fasa dari sumber catu daya masuk kedalam rangkaian pengatur daya. Pada rangkaian ini terdapat triak yang akan mencacah tegangan, besar kecilnya tegangan yang dihasilkan dari keluaran triac tegantung dengan waktu yang digunakan untuk membuka gate pada triak.

Besarnya waktu ini ditentukan oleh rangkaian $\mathrm{R}-\mathrm{C}$ pada rangkaian pengatur daya, jika tegangan pada tiap-tiap fasa tersebut memiliki besar frekuensi $50 \mathrm{~Hz}$ maka waktu yang dibutuhkan untuk mencapai 1 gelombang penuh (periode) yaitu sebesar 1:50 $=0.02$ detik, dan untuk mencapai setengah gelombang yaitu 0.01 detik.

Triac mencacah pada gelombang puncak dan lembah dalam arti melakukan dua kali pencacahan dalam satu gelombang penuh, atau satu kali switching pada setengah gelombang penuh. Seperti penjelasan diatas memerlukan waktu 0.01 detik jadi triac melakukan switching antara waktu 0-0.01 detik. Semakin cepat waktu switching yang dilakukan maka semakin besar pula nilai tegang yang di keluarkan oleh triac, jika switching dilakukan pada tepat waktu 0 detik tegangan output akan keluar maksimum seperti tegangan input, dan jika switch dilakukan pada waktu 0,01 detik tegangan yang dikeluarkan bernilai 0 volt.

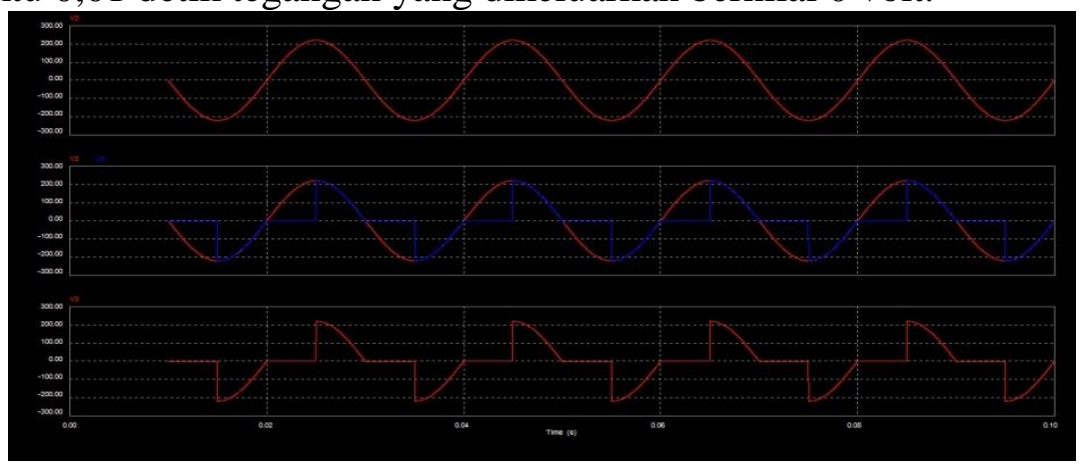

Gambar 1 Gelombang input dan output triac.

Pada gambar diatas adalah gelombang input (gambar pertama), dan gambar hasil pencacahan (gambar ketiga) pada triac. Terlihat bahwa besar luasan 
gelombang tersebut berbeda maka besar tegangan rata-rata yang dihasikan pun akan berbeda (lebih kecil dari tegangan input). Gambar diatas adalah ketika triac mendapat trigger 0.005 detik atau saat mencapai seperempat dari satu gelombang penuh.

Pencacahan nilai tegangan tersebut terjadi pada setiap fasa, dengan syarat besar tegangan besar beda sudut antar fasa dan frekuensi harus tetap seimbang seperti tegangan input. Karena bila terdapat selisih yang terlalu besar pada tegangan motor dapat tidak berputar karena beda potensial tiap-tiap fasa tidak seimbang.

Rangkaian ini nilai waktu switching ditentukan oleh rangkaian R-C atau (resistor dan kapasitor). Dan pada rangkaian yang akan dibuat perubahan nilai R-C dengan cara menggunakan Potensiometer atau Variable Resistor untuk merubah nilai dari R. rumus dari waktu switching yaitu $\mathrm{t}=\mathrm{R} \times \mathrm{C}$.

Karena nilai tegangan output tiap-tiap fasa dan selisih sudut tiap-tiap fasa harus sama besarnya, maka terdapat rangkaian khusus untumenyatukan tiga potensio, agar kondisi output dapat terpenuhi.

Sistem pengoperasian analog dapat dengan langsung memutar potensio tersebut. Dan cara digital yaitu dengan menggunakan tombol yang telah terhubung dengan relay, relay ini terhubung dengan rangkaian resistor dan akan merubah nilai resistansi dari rangkaian R-C. Pengoperasian ini dapat dirubah sesuai kebutuhan semisal digunakan untuk mengatur motor pada mesin Air Conditioning fungsi PC dapat digantikan dengan sensor suhu, atau sensor lain.

\section{Motor Induksi}

Motor induksi yaitu motor satu fasa maupun tiga fasa yang akan diatur kecepatan putaranya oleh rancangan VSD yang akan di buat oleh penulis, kecepatan putaran maksimum apabila motor mendapat tegangan maksimum, dan akan berkurang kecepatan motor apabila kita memberikan suplay tegangan kurang. Beasar tegangan yang masuk ke motor tergantun dari tegangan output dari triac.

\section{Perancangan Sistem}

Perancangan sistem ini dimulai dari menentukan rangkaian time

R-C selanjutnya menggabungkan rangkaian tersebut dengan rangkaian pembagi tegangan dan sistem tersebut yang akan digunakan untuk mengatur tegangan yang masuk pada motor.

\section{Power Supplay}

Power supplay pada rangkaian ini berfungsi sebagai sumber tegangan DC untuk sumber penyalaan relay, prinsip power suplay ini yaitu merubah tegangan AC 220 $\mathrm{V}$ pada sisi input alat dan akan di turunkan menjadi 12 VAC yang selanjutnya akan di searahkan oleh diode Bridge dan akan keluar sebagai tegangan DC yang masih memiliki ripple, dan selanjutnya akan di saring oleh kapasitor untuk mengurangi ripple dan akan di regulasi oleh IC 7812 supaya tegangan output setabil 12 V DC 


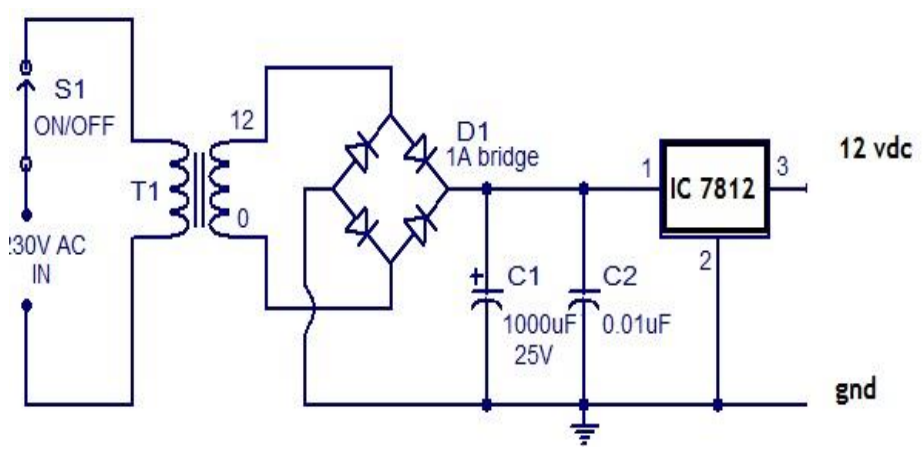

Gambar 2 Rangkaian Power supplay

\section{Rangkaian Time Analog}

Rangkaian ini tersusun dari rangkaian potensiometer yang di seri dengan kapasitor $40 \mathrm{uF}$ di seri dengan $50 \mathrm{Kohm}$, pada rangkaian ini berfungsi sebagai pembagkit trigger pulsa trigger. Selanjutnya output dari kapasitor akan keluar dan besarnya tegangan yang keluar dibatasi oleh diac supaya sinyal dapat terbentuk secara teratur.

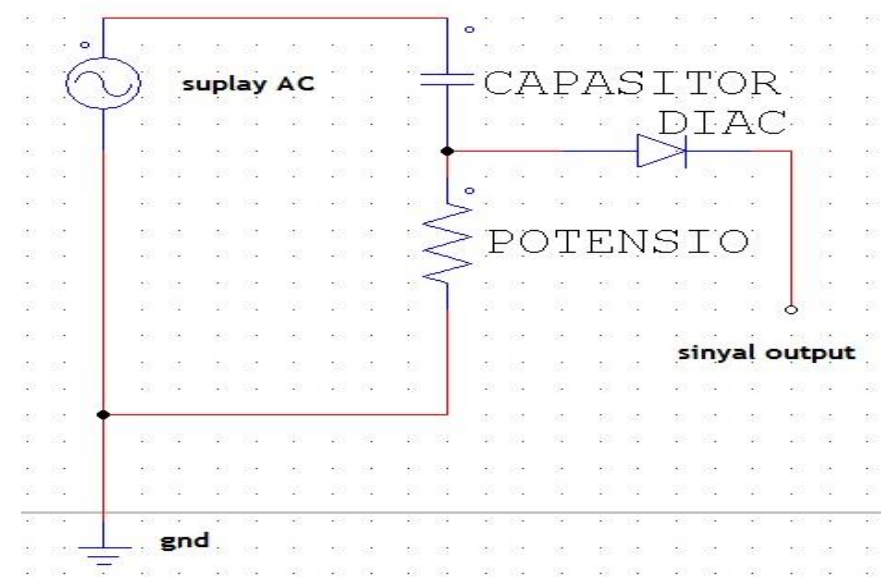

Gambar 3 Rangkaian time R-C untuk trigger triac

Besar frekuensi sinyal output diatas bergantung dengan besarnya nilai resistansi dan kapasitansi dari resistor dan kapasitor, besarnya output tegangan bergantung dengan diac yang digunakan.

Untuk frekuensi sinyal output yaitu dengan rumus $\mathbf{t}=\mathbf{R} \mathbf{X} \mathbf{C}$ dimana $\mathrm{t}=$ besar frekuensi atau waktu trigger $\mathrm{R}=$ resistansi dan $\mathrm{C}=$ kapasitansi.

Pada alat ini menggunakan resistor $50 \mathrm{~K}$ ohm dan kapasitor $40 \mathrm{u} \mathrm{F}$ sehingga besar frekuensi saat potensio maksimal yaitu:

$\mathbf{t}=50.000 \times 0.000004$ sehingga besar

$\mathrm{t}=0.02$ detik per satu sinyal

Dan ketika potensio minimal resistansi $0 \mathrm{ohm}$ maka:

$\mathrm{t}=0 \times 0.000004$

$\mathrm{t}=0$ detik

Dengan tegangan output sebesar kapasitas diac yaitu $5 \mathrm{~V}$. 
Selanjutnya sinyal output ini yang dimanfaatkan untuk mengatur dari output triac, untuk lebih jelasnya penulis menggunakan simulasi PSIM untuk mempermudah dalam menganalisa bentuk gelombang maupun periode gelombang.

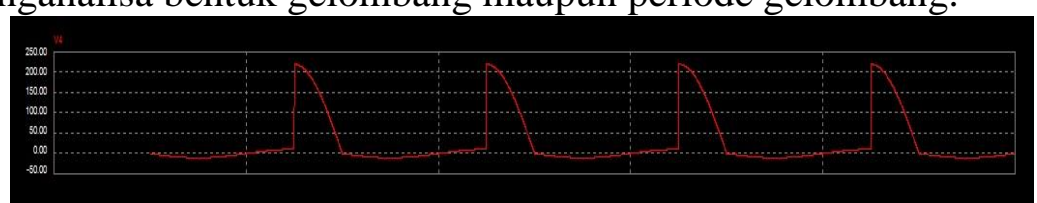

Gambar 4 Output gelombang pada rangkaian R-C

\section{Blok Diagram Rancangan}

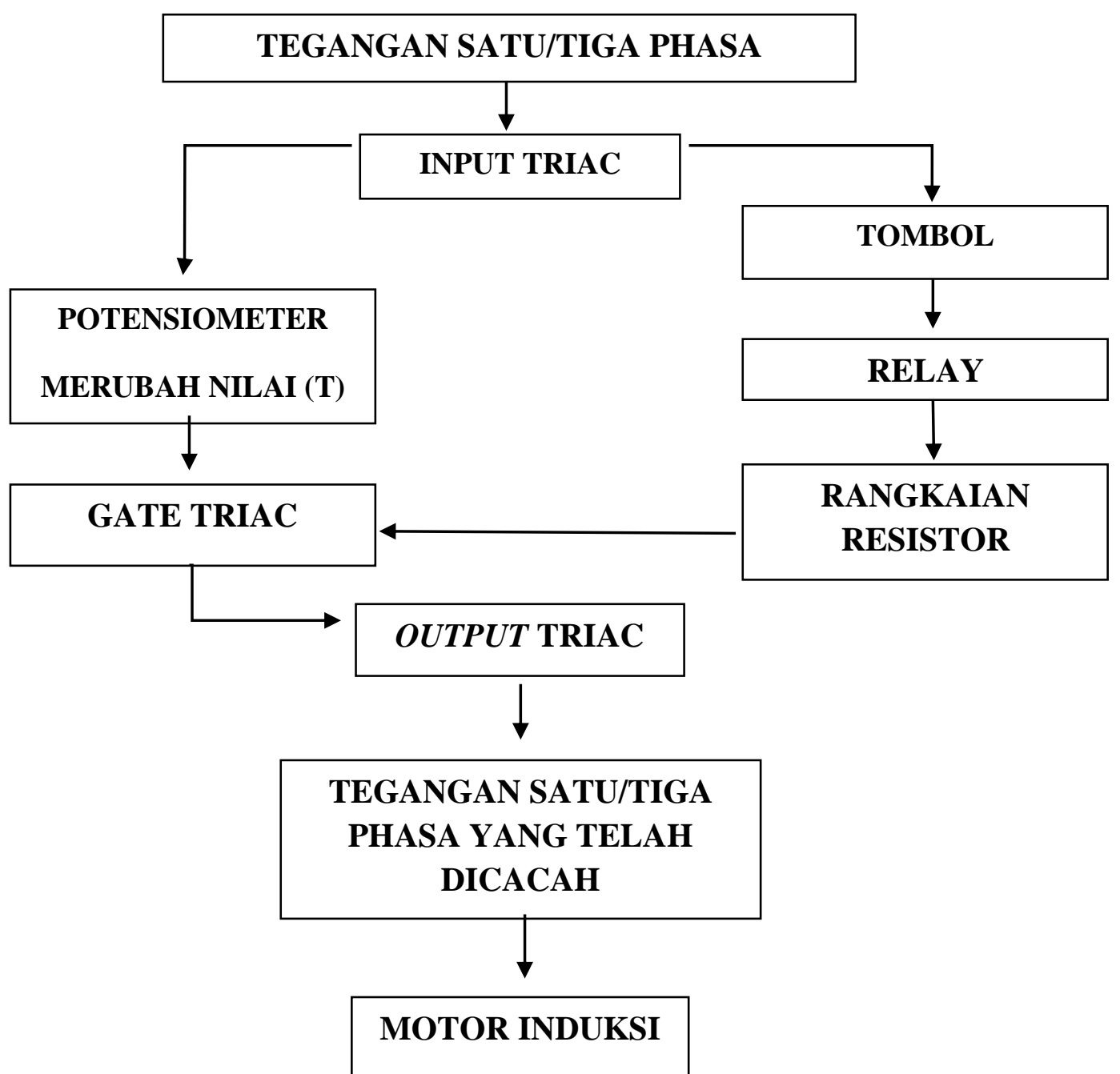


Flow Chart Rancangan

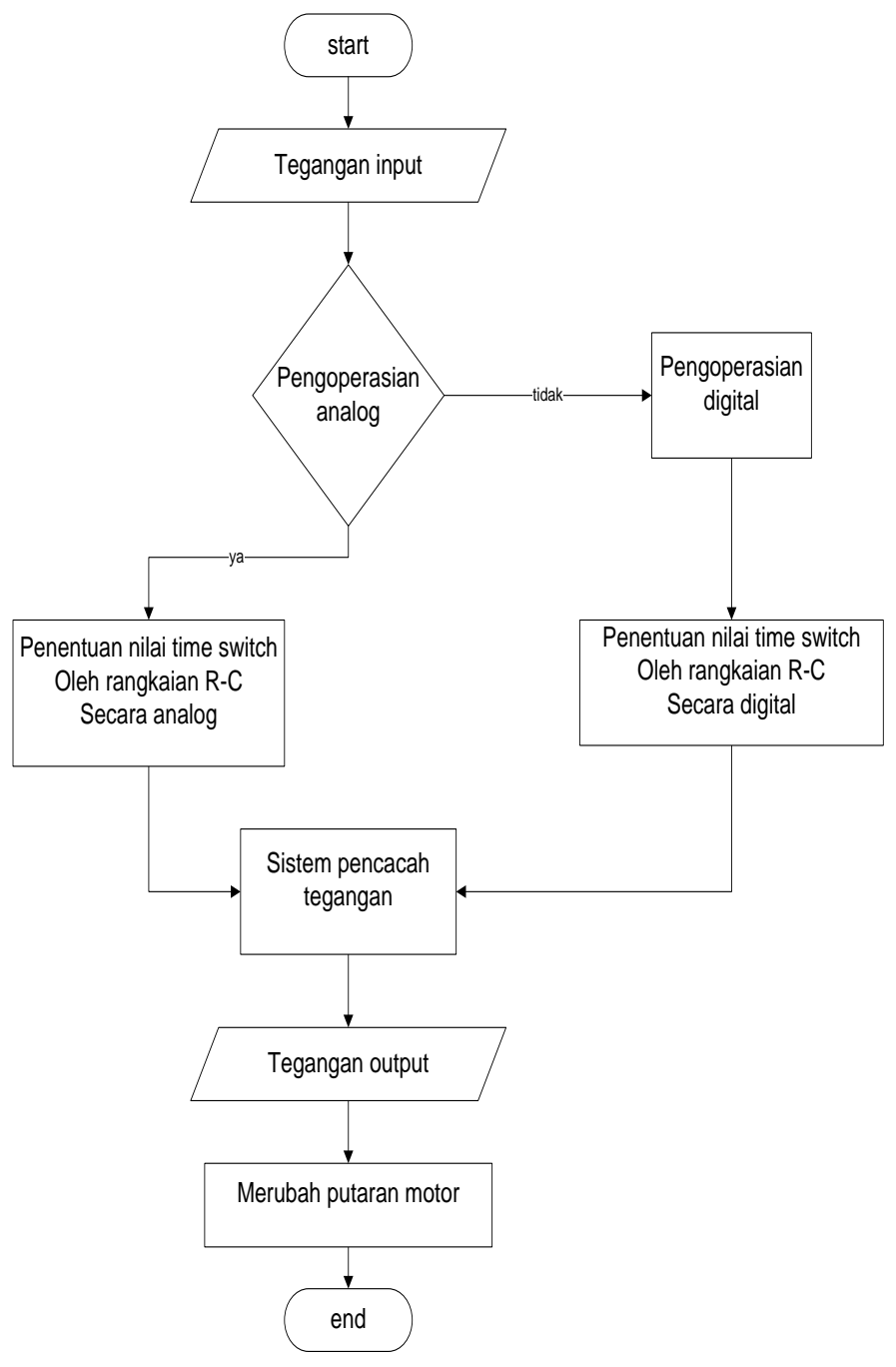

\section{PENGUJIAN DAN ANALISA}

Bab ini akan membahas tentang pengujian terhadap perencanaan dari sistem yang telah dibuat pada Bab III sebelumnya. Pengujian ini dilakukan untuk mengetahui kinerja dari sistem dan untuk mengetahui apakah sistem yang telah dibuat sesuai dengan perencanaan atau belum. Adapun tahap-tahap pengujian yang akan dilakukan adalah sebagai berikut :

1. Pengujian input dan output tegangan 1 dan 3 phasa secara analog.

2. Pengujian input dan output tegangan 1 dan 3 phasa secara digital.

3. Pengujian perubahann tegangan terhadap kecepatan putar motor.

4.

\section{Pengujian Input dan Output Tegangan 1 dan 3 Phasa Secara Analog.}

Pengujian ini dilakukan untuk menguji input tegangan satu dan tiga fasa, input ini akan diolah dalam rangkaian pencacah daya dan kemudian kita dapat 
mengatur besar output tegangan dengan dengan cara analog (memutar potensio) pada alat yang telah ada.

Di bawah ini gambar pengoprasian VSD dengan input satu atau tiga fasa.

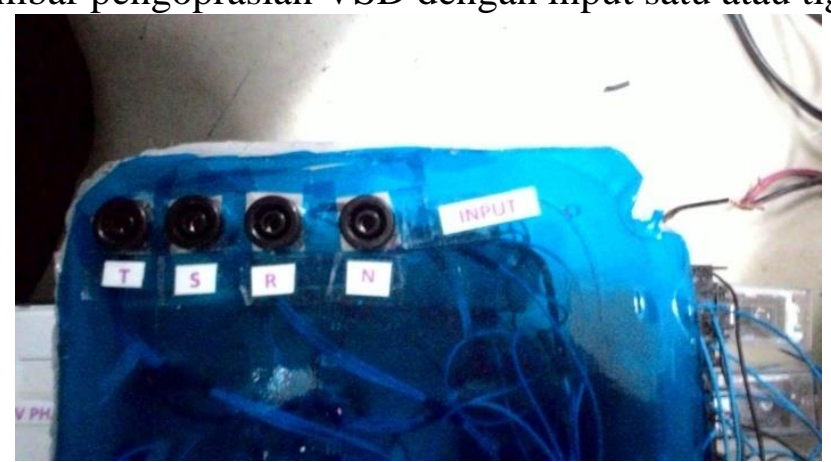

Gambar 5 input tegangan rancangan VSD

\section{Pengujian Input dan Output Tegangan 1 dan 3 Phasa Secara Digital.}

Pengujian ini dilakukan untuk menguji input tegangan satu dan tiga fasa, input ini akan diolah dalam rangkaian pencacah daya dan kemudian kita dapat mengatur besar output tegangan dengan dua cara yaitu dengan cara digital yaitu dengan cara menekan tombol pada alat yang telah ada.

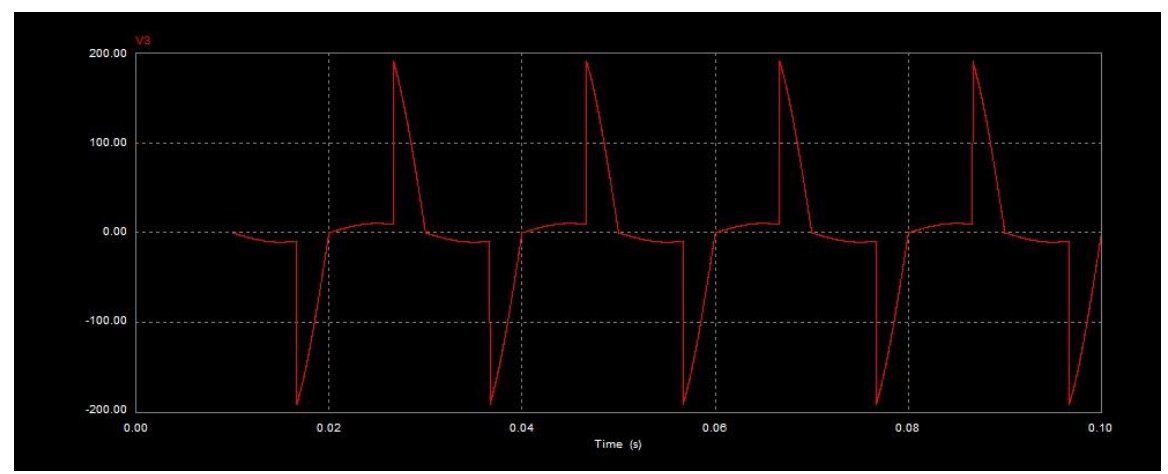

Gambar 6 Gelombang output speed

\section{Pengujian Perubahan Tegangan Terhadap Kecepatan Putaran Motor}

Pengujian ini dilakukan untuk mengetahui perubahan kecepatan motor terhadap perubahan tegangan output yang telah dihasilkan oleh VSD.

Cara melakukan percobaan ini sama dengan percobaan diatas namun kali ini kita menghubungkan tegangan output ke pada motor satu fasa atau motor tiga fasa.

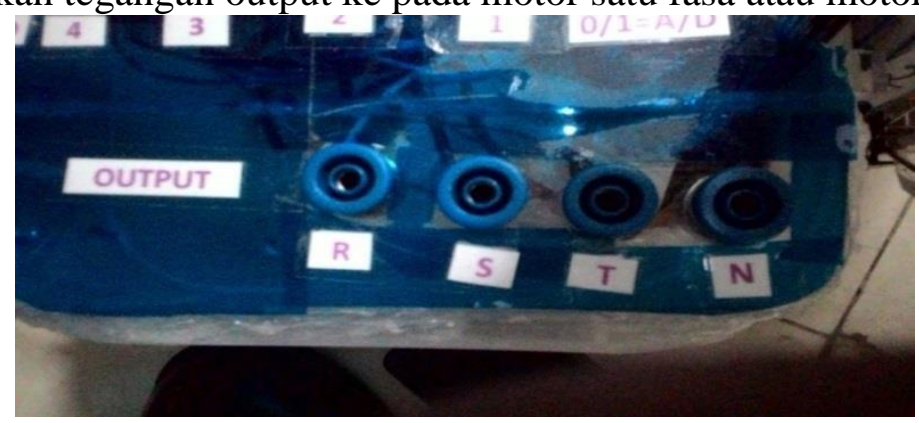

Gambar 7 output tegangan VSD 


\section{KESIMPULAN}

\section{Kesimpulan}

Dengan merancang Variable Speed Drive dengan sistem pencacah tegangan satu fasa dan tiga fasa penulis memiliki beberapa kesimpulan yaitu:

1. Kita dapat mengatur kecepatan motor selain menggunakan frekuensi yang dirubah jaga dapat menggunakan input tegangan yang bervariasi.

2. Karakteristik motor AC satu fasa lebih sulit melakukan soft start dibanding motor AC tiga fasa dan juga pada power motor tiga fasa terbukti lebih halus dan juga lebih kuat sehingga peralatan yang membutuhkan kecepatan dan kekuatan yang konstan lebih sering menggunakan motor tiga fasa.

\section{DAFTAR PUSTAKA}

Edminister, Joseph . 2007. "Rangkaian Listrik Edisi 4". Yogyakarta.

Mismail, Budiono. 2010. "Dasar Teknik Elektro" . Jakarta.

Frank, D Petuzzela. 2009. "Elektro Industri”. Jakarta.

Charles, Siskind. 1995. "Electrical Machining". Graw Hill kogakusha.

Wati, Dwi Ana Ratna, SISTEM KENDALI CERDAS, Graha Ilmu, Yogyakarta. 2010.

B.L Theraja, A TEXT BOOK OF ELECTRICAL TECHNOLOGY, Vol II Chapter 29. 